\title{
Role of IFN-gamma and IL-6 in a protective immune response to Yersinia enterocolitica in mice Gianluca Matteoli ${ }^{\dagger 1}$, Edda Fahl ${ }^{\dagger 1}$, Philipp Warnke ${ }^{\dagger 1}$, Steffen Müller ${ }^{1}$, Michael Bonin ${ }^{2}$, Ingo B Autenrieth ${ }^{1}$ and Erwin Bohn*1
}

Address: ${ }^{1}$ Institut für Medizinische Mikrobiologie und Hygiene, Universitätsklinikum Tübingen, Tübingen, Germany and ${ }^{2}$ IZKF Microarray Facility Medizinische Genetik, Universitätsklinikum Tübingen, Tübingen, Germany

Email: Gianluca Matteoli - gianluca.matteoli@ifom-ieo-campus.it; Edda Fahl - edda.fahl@med.uni-tuebingen.de; Philipp Warnke - p.warnke@web.de; Steffen Müller - Steffen.Mueller@Stratagene.Com; Michael Bonin - michael.bonin@gmx.net; Ingo B Autenrieth - ingo.autenrieth@med.uni-tuebingen.de; Erwin Bohn* - erwin.bohn@med.uni-tuebingen.de

* Corresponding author †Equal contributors

Published: 19 September 2008

BMC Microbiology 2008, 8:153 doi:10.1/86/147|-2180-8-153
Received: 9 April 2008

Accepted: 19 September 2008

This article is available from: http://www.biomedcentral.com//47/-2/80/8/I53

(c) 2008 Matteoli et al; licensee BioMed Central Ltd.

This is an Open Access article distributed under the terms of the Creative Commons Attribution License (http://creativecommons.org/licenses/by/2.0), which permits unrestricted use, distribution, and reproduction in any medium, provided the original work is properly cited.

\begin{abstract}
Background: Yersinia outer protein (Yop) $\mathrm{H}$ is a secreted virulence factor of Yersinia enterocolitica $(Y e)$, which inhibits phagocytosis of $Y e$ and contributes to the virulence of $Y e$ in mice. The aim of this study was to address whether and how YopH affects the innate immune response to $\mathrm{Ye}$ in mice.

Results: For this purpose, mice were infected with wild type $\mathrm{Ye}\left(\mathrm{pYV}^{+}\right)$or a $\mathrm{YopH}$-deficient $\mathrm{Ye}$ mutant strain $(\Delta y o p H)$. CDI l b ${ }^{+}$cells were isolated from the infected spleen and subjected to gene expression analysis using microarrays. Despite the attenuation of $\Delta y o p H$ in vivo, by variation of infection doses we were able to achieve conditions that allow comparison of gene expression in $\mathrm{pYV}^{+}$and $\triangle y o p H$ infection, using either comparable infection courses or splenic bacterial burden. Gene expression analysis provided evidence that expression levels of several immune response genes, including IFN- $\gamma$ and IL-6, are high after $\mathrm{pYV}^{+}$infection but low after sublethal $\Delta y o p H$ infection. In line with these findings, infection of IFN- $\gamma \mathrm{R}^{-/-}$and IL-6-/- mice with $\mathrm{pYV}^{+}$or $\Delta y o p H$ revealed that these cytokines are not necessarily required for control of $\Delta y o p H$, but are essential for defense against infection with the more virulent $\mathrm{PYV}^{+}$. Consistently, IFN- $\gamma$ pretreatment of bone marrow derived macrophages (BMDM) strongly enhanced their ability in killing intracellular Ye bacteria.
\end{abstract}

Conclusion: In conclusion, this data suggests that IFN- $\gamma$-mediated effector mechanisms can partially compensate virulence exerted by $\mathrm{YopH}$. These results shed new light on the protective role of IFN- $\gamma$ in Ye wild type infections.

\section{Background}

Yersinia enterocolitica (Ye) is an enteropathogenic bacterium which causes gastrointestinal disorders such as, enteritis, enterocolitis and extraintestinal manifestations such as lymphadenitis, reactive arthritis, erythema nodosum, uveitis and septicaemia $[1,2]$. Pathogenic Ye strains carry a 70-kb plasmid (pYV), which is essential for the pathogenicity and encodes a type III secretion system (TTSS), Yersinia outer proteins (Yops) and YadA [3]. The TTSS enables extracellularly located yersiniae to translocate at least six effector Yops directly into host cells [3]. The Yops interfere with different signaling pathways 
involved in the regulation of the actin cytoskeleton, phagocytosis, apoptosis and in the inflammatory response, thus favoring survival of the bacteria in an extracellular tissue compartment [3]. YopH, YopE, YopT, and YopO/YpkA disturb cytoskeletal dynamics and thereby inhibit phagocytosis by polymorphonuclear leukocytes and macrophages [4-7]. YopH, a tyrosine phosphatase, causes disruption of focal adhesion complex structures and inhibits the oxidative burst $[7,8]$. Among others, the host cell targets of YopH in epithelial cells are the focal adhesion proteins Crk-associated substrate (p130Cas) and focal adhesion kinase (FAK) and in macrophages p130Cas, Fyn-binding protein (Fyb) and SKAP-HOM [812]. YopH mutants, which are unable to bind p130Cas, do not localize to focal complex structures in infected cells [13]. These YopH mutants showed reduced virulence in mice, suggesting that binding to p130Cas and/or Fyb is biologically relevant in Yersinia infections. Other functions of YopH include the inhibition of the phosphatidylinositol 3 kinase (PI3K)/Akt signaling pathway which is activated in macrophages upon interaction with Yersinia [14], and downstream effects such as expression of the chemokine monocyte chemoattractant protein-1 (MCP-1, CCL2), an important chemotactic factor for macrophages [14].

The phosphatase activity of YopH inhibits the ability of $\mathrm{T}$ cells to produce cytokines and proliferate, as well as the ability of B cells to express the B-cell co-stimulatory receptor CD86, possibly by dephosphorylating critical tyrosine residues on signaling proteins involved in $\mathrm{T}$ - and $\mathrm{B}$-cell activation [14-17]. The biological relevance of YopH is underlined by different reports demonstrating that the lack of YopH results in reduced virulence of Yersinia in mice [18-21].

In this study, we addressed whether and how YopH might affect the innate immune response in mice. Upon infection with $Y$. enterocolitica $\mathrm{O} 8$ strain WA-314 $\left(\mathrm{pYV}^{+}\right)$or a YopH deletion mutant $(\triangle y o p H)$ alterations in gene expression in $\mathrm{CD} 11 \mathrm{~b}^{+}$cells was analyzed. These cells include mostly granulocytes and macrophages and to a lower extent dendritic cells and NK cells. CD11 b ${ }^{+}$cells were chosen because they are the most important spleen cell subpopulations involved in innate immune responses. The data reported herein provide strong evidence that IFN- $\gamma$ and IL- 6 are not necessarily required for clearance of $Y$. enterocolitica $\Delta y o p H$ and that IFN- $\gamma$ compensates YopHmediated immune evasion mechanisms in macrophages.

\section{Results}

YopH deletion attenuates Yersinia enterocolitica in mice In this study, we addressed how the virulence factor YopH affects the early innate immune responses to Yersinia enterocolitica in vivo. For this purpose, we defined the inocula leading to sublethal and lethal infection after intravenous infection with $\mathrm{pYV}^{+}$and $\Delta y o p H$. Infection of $\mathrm{C} 57 \mathrm{BL} / 6$ mice with $5 \times 10^{3} \mathrm{pYV}^{+}$or $5 \times 10^{4} \Delta$ yopH caused a sublethal infection, while $5 \times 10^{4} \mathrm{pYV}^{+}$or $5 \times 10^{6} \Delta y o p H$ resulted in a lethal course of infection (Figure 1A). Sublethal infection with $\mathrm{pYV}^{+}$resulted in significantly higher bacterial counts in the spleen at day 1 p.i. compared with $\Delta y o p H$, while lethal infection with $\mathrm{pYV}^{+}$or $\Delta y o p H$ resulted in comparable bacterial splenic counts (Figure 1B).

To address whether the sublethal and lethal infection with $\mathrm{pYV}^{+}$and $\Delta y o p H$ affect the cells involved in innate immune responses, the number of macrophages $\left(\mathrm{CD} 11 \mathrm{~b}+\mathrm{F} 4 / 80^{+}\right)$, granulocytes $\left(\mathrm{CD} 11 \mathrm{~b}+\mathrm{Ly}_{6} \mathrm{G}^{+}\right)$and dendritic cells $\left(\mathrm{CD} 11 \mathrm{~b}^{+} \mathrm{CD} 11 \mathrm{c}^{+}\right)$in the spleen was determined at day 1 p.i. The total number of macrophages was significantly increased one day after the sublethal infection with both $\mathrm{pYV}^{+}$and $\Delta y o p H$ compared with mockinfected mice. In contrast, under lethal conditions a significant increase in the number of macrophages was only detected after infection with $\mathrm{pYV}^{+}$(Fig. 1C). The number of granulocytes was significantly increased after sublethal as well as lethal infection with $\mathrm{pYV}^{+}$but not after sublethal or lethal $\Delta y o p H$ infection (Fig. 1D). The number of dendritic cells was similar in all conditions one day after infection (data not shown).

From this data we can conclude that by variation of the inoculum for $\mathrm{pYV}^{+}$and $\Delta y o p H$ infections, conditions can be achieved that lead either to comparable infection course (lethal or sublethal) or to comparable bacterial burden in the spleen as well as to comparable alterations in the composition of splenic cell populations. These changes have to be considered when gene expression patterns are compared in $\mathrm{pYV}^{+}$and $\Delta y o p H$ infections.

\section{Gene expression in $\mathrm{CDI} / \mathrm{b}^{+}$cells after Yersinia infection}

To analyse whether YopH affects gene expression in cells involved in the innate immune response, splenic CD11b+ cells were purified by MACS to $96-98 \%$ from mice one day p.i. RNA was extracted and subjected to gene expression analysis using Affymetrix MG-U74Av2 microarrays. First, we identified all genes which were more than 3-fold higher or more than 3-fold lower expressed after infection with either a sublethal or a lethal dose of $\mathrm{pYV}^{+}$or $\Delta y o p H$ compared to uninfected mice resulting in 1428 probe sets. These probe sets were used in the following analyses.

\section{Gene expression analyses reveal differences between pYV+ and $\Delta y o p H$ infection}

Two approaches were selected, to help identify immune response genes whose expression differs after infection with $\mathrm{pYV}^{+}$and $\Delta y o p H$. In the first approach, gene expression of $\mathrm{CD}_{11 \mathrm{~b}^{+} \text {cells from mice after sublethal } \mathrm{pYV}^{+} \text {and }}$ sublethal $\triangle y o p H$ infection was compared. This method 

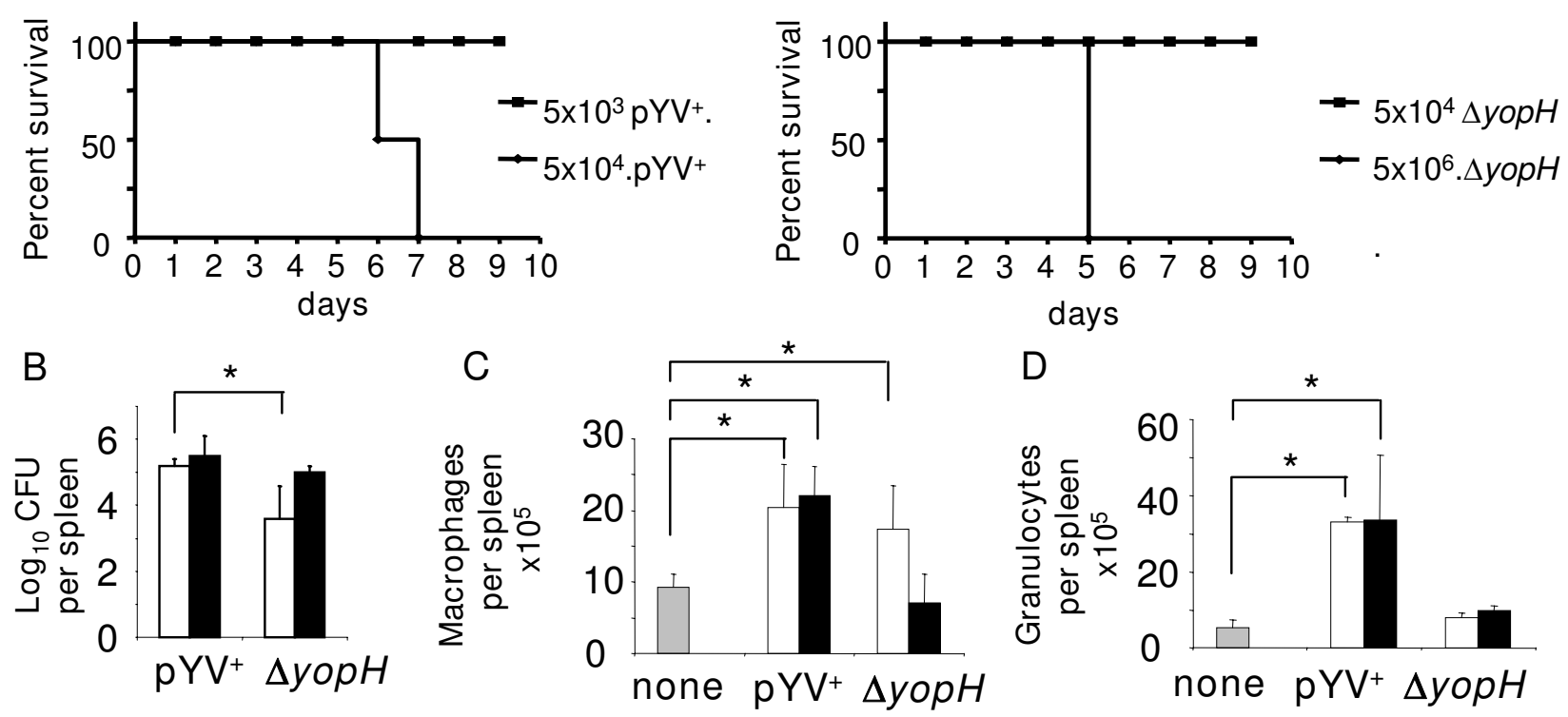

$\checkmark$ Sublethal infection dose

- Lethal infection dose

\section{Figure I}

Infection of mice with pYV+ and $\Delta y o p H$. (A) Survival curve of C57BL/6 mice upon i.v. infection with $5 \times 10^{3}$ or $5 \times 10^{4}$ $\mathrm{PYV}^{+}$, or with $5 \times 10^{4}$ or $5 \times 10^{6} \Delta y o p H(B)$ The bacterial numbers in the spleen of mice and total number of (C) macrophages and (D) granulocytes in the spleen was determined $24 \mathrm{~h}$ after infection. The data were from two independent the means \pm standard deviation of at least ten mice per group. Asterisks indicate significant differences $(p<0.05, A$ and B, logrank test; $C$, Wilcoxon rank test, D and E, One-Way ANOVA with Dunnett test) between the compared groups.

was used to compare gene expression associated with similar outcome of disease; however, the different bacterial splenic counts and different composition of CD11b+subpopulations has to be considered in subsequent comparative analyses. In a second approach, we compared gene expression of $\mathrm{CD} 11 \mathrm{~b}^{+}$cells from mice with comparable bacterial splenic counts after infection with $\mathrm{pYV}^{+}$and $\Delta y o p H$. To accomplish this, we compared mice after sublethal $\mathrm{pYV}^{+}$and lethal $\Delta y o \mathrm{pH}$ infection resulting in similar splenic bacterial counts one day p.i. $\left(\sim 10^{5} \mathrm{CFU}\right)$ in the spleen. In both approaches k-means cluster analysis was carried out to characterize groups of co-expressed genes. Genes which were more than 3-fold differentially expressed between $\mathrm{pYV}^{+}$and $\Delta y o p H$ infection are listed in Additional file 1 and 2 and depicted as heat maps in Figure 2.

The immune response genes identified by approach I (sublethal $\mathrm{pYV}^{+}$infection versus sublethal $\Delta y o p H$ infection) comprised genes which were more highly expressed after both sublethal $\mathrm{pYV}^{+}$and sublethal $\Delta y o p H$ infection, as compared with mock-infected mice. However, the expression level of these genes was more than 3-fold higher after sublethal $\mathrm{pYV}^{+}$infection (Table 1, column 1) as compared with sublethal $\Delta y o p H$ infection (Table 1, column 3). These genes were designated as Group 1 and included genes encoding e.g. IFN- $\gamma$, IL-6, histidine decarboxylase and iNOS (Table 1, Figure 2A, Cluster A1 and Additional file 1).

As the bacterial splenic load after sublethal pYV+ infection was lower than that after sublethal $\Delta y o p H$ infection at day 1 p.i., we cannot exclude the possibility that the different gene expression is due to the different bacterial load in the spleen.

Therefore, in approach II we first compared expression of Group 1 genes in mice after sublethal pYV+ (Table 1, column 1) and lethal $\Delta y o p H$ infection (Table 1, column 4) which resulted in similar splenic bacterial counts 1 day p.i. The data revealed Group 1A, which included genes with comparable expression after sublethal $\mathrm{pYV}^{+}$and lethal $\Delta y o p H$ infection such as, IFN- $\gamma$ and histidine decarboxylase, and Group 1B, which included genes which were expressed less after lethal $\Delta y o p H$ infection as compared with sublethal $\mathrm{pYV}+$ infection. 
A

$$
\begin{array}{llcc}
\text { Subl } & \text { Leth } & \text { Subl } & \text { Leth } \\
\mathrm{pYV}^{+} & \mathrm{pYV}^{+} & \Delta y o p H & \Delta y o p H
\end{array}
$$

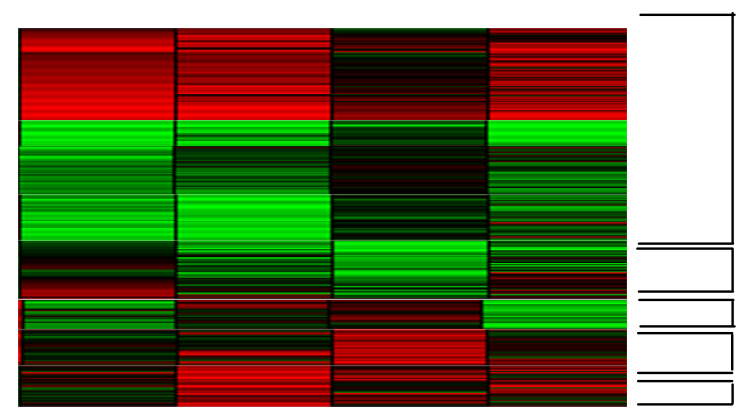

B

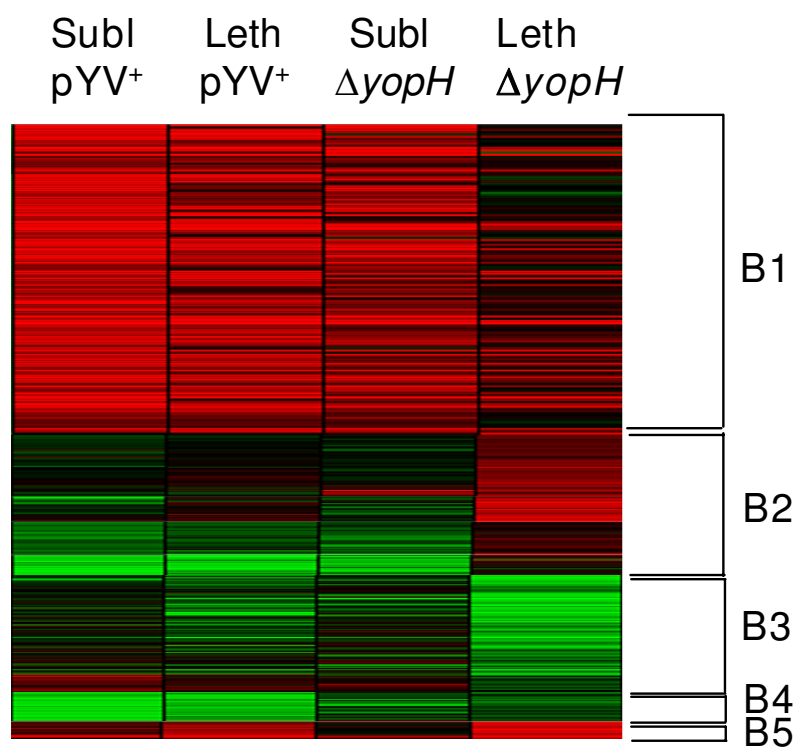

C

IFN- $\gamma$

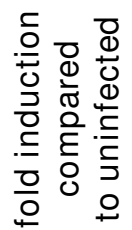

IL-6

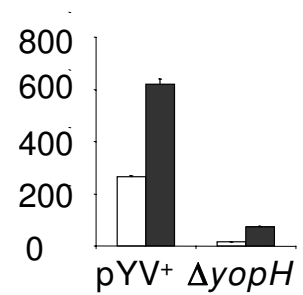

IL-12p35

80

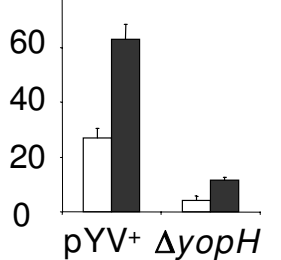

MARCO

20

15

10

5

0

$\mathrm{pYV}^{+} \Delta y o p H$

\section{$\square$ Sublethal infection dose}

\section{Lethal infection dose}

\section{Figure 2}

Comparison of gene expression between mice infected with $\mathbf{p Y V}^{+}$and $\Delta y o p H$. Microarray analysis of $\mathrm{CDI}_{\mathrm{I}} \mathrm{b}^{+}$cells isolated from spleen of mice infected with $\mathrm{pYV}^{+}$or $\Delta y o p H$ for one day. All probe sets are displayed whose SLR ratio between infection with $\mathrm{pYV}^{+}$and $\Delta y o p H$ for one day was $>1.49$ or $<-1.49$. Heat maps indicate increased (red) or decreased (green) expression of genes in CDI l b+ cells one day after infection of mice compared to CDI I b cells from uninfected mice. The heatmaps indicate genes differentially expressed and clustered in different groups: (A, approach I) sublethal $\mathrm{pY}^{+}$infection versus sublethal $\Delta y o p H$ infection; (B, approach II) sublethal $\mathrm{pYV}^{+}$versus lethal $\Delta y o p H$ infection. (C) $C D I I b^{+}$cells were enriched from uninfected mice and from mice infected for I day with $\mathrm{PYV}^{+}$or $\Delta y o p H$, and RNA was extracted. mRNA expression of IFN- $\gamma$, IL6, IL-I2p35 and MARCO was analysed and normalized to RPL8 mRNA expression. The data represent the fold induction of mRNA expression compared to CDI Ib cells from uninfected mice. Representative data for three independent experiments are shown. 
Table I: Immune response genes differentially expressed after infection with $\mathrm{pYV}^{+}$compared to $\Delta$ yopH

\begin{tabular}{|c|c|c|c|c|}
\hline & $\begin{array}{l}\mathrm{pYV}^{+}\left(5 \times 10^{3}\right) \\
\text { fold expression } \\
\text { compared to } \\
\text { uninfected }\end{array}$ & $\begin{array}{l}\mathrm{pYV}^{+}\left(5 \times 10^{4}\right) \\
\text { fold expression } \\
\text { compared to } \\
\text { uninfected }\end{array}$ & $\begin{array}{c}\Delta y o p H\left(5 \times 10^{4}\right) \\
\text { fold expression } \\
\text { compared to } \\
\text { uninfected }\end{array}$ & $\begin{array}{c}\Delta \text { yopH }\left(5 \times 10^{6}\right) \\
\text { fold expression } \\
\text { compared to } \\
\text { uninfected }\end{array}$ \\
\hline \multicolumn{5}{|l|}{ Group I } \\
\hline \multicolumn{5}{|l|}{ A } \\
\hline $\mathrm{CXCL2}$ & 39.4 & 45.3 & 7.5 & 36.8 \\
\hline $\mathrm{CCL} 2$ & 13 & 22.6 & 4.6 & 48.5 \\
\hline Histidine decarboxylase & 3.5 & 3.8 & 1.2 & 4 \\
\hline IFN- $\gamma$ & 12.1 & 36.8 & 3.0 & 13.3 \\
\hline IL-I2A & 21.1 & 36.8 & 1.2 & 8.6 \\
\hline TNF- $\alpha$ & 9.9 & 10.6 & 4 & 10.6 \\
\hline \multicolumn{5}{|l|}{ B } \\
\hline IL6 & 19.7 & 32.0 & 9.2 & 5.2 \\
\hline INOS & 4.6 & 3.7 & 1.3 & 1.7 \\
\hline ILIA & 90.5 & 119.4 & 14.9 & 26.0 \\
\hline CXCLI & 12.1 & 21 & 3 & 7 \\
\hline \multicolumn{5}{|l|}{ Group 2} \\
\hline \multicolumn{5}{|l|}{ A } \\
\hline SAA3 & 1.1 & 1.3 & 0.4 & 3.5 \\
\hline Lactotransferrin & 0.4 & 0.5 & 0.3 & 2.8 \\
\hline LBP & 0.8 & 1 & 0.5 & 2.8 \\
\hline MARCO & 0.6 & 0.4 & 1.7 & 8.6 \\
\hline Orosomucoid & 0.4 & 0.7 & 0.7 & 3.3 \\
\hline $\begin{array}{l}\text { Peptidoglycan recognition } \\
\text { protein }\end{array}$ & 0.6 & 0.9 & 0.8 & 2.6 \\
\hline \multicolumn{5}{|l|}{ B } \\
\hline CCLI7 & 2.1 & 10.6 & 1.2 & 6.5 \\
\hline ILIO & 1.2 & 4 & 2 & 8.6 \\
\hline \multicolumn{5}{|l|}{ Group 3} \\
\hline CXCL9 & 21.1 & 14.9 & 9.2 & 3.7 \\
\hline IIGPI & 32 & 39.4 & 24.3 & 8.6 \\
\hline MXI & 6.5 & 6.5 & 4 & 1.2 \\
\hline WARS & 4.6 & 3.7 & 4.6 & 1.9 \\
\hline VEGFA & 6.5 & 6.5 & 5.7 & 2.3 \\
\hline
\end{tabular}

Approach II also revealed genes which were more highly expressed after lethal $\Delta y o p H$ infection compared to sublethal $\mathrm{pYV}^{+}$infection (Table 1, Group 2, Figure 2B, Cluster B2). While the expression of several of these genes (Group 2A) which include acute phase reactants such as serum amyloid alpha 3 (SAA3), lipopolysaccharide binding protein (LBP) and other genes such as MARCO, peptidoglycan recognition protein and lactotransferrin were increased only after lethal infection with $\Delta y o p H$ compared to uninfected mice, others (Group 2B), e.g., IL-10 and CCL17 increased only after lethal infection either with $\mathrm{pYV}^{+}$or $\Delta y o p H$ as compared to uninfected mice.

Furthermore, approach II revealed genes (interferon induced genes such as interferon inducible GTPase 1 (IIGP1), CXCL9, as well as VEGF- $\alpha$ ) which were highly induced after Yersinia infection but which were lower expressed after lethal $\Delta y o p H$ infection compared to sublethal or lethal $\mathrm{pYV}^{+}$infection.
To ensure that the results obtained by microarray analyses can be reproduced by other methods, mRNA expression analyses for IFN- $\gamma$, IL-6, IL-12p35 and MARCO were performed by Real-time RT PCR. The results obtained were comparable to those obtained by microarraray analyses (Figure 2C).

\section{IFN- $\gamma$ and IL-6 are not necessarily required for clearance of Y. enterocolitica $\Delta$ yopH}

The data presented above revealed that in self-limiting infections (sublethal), the expression of both IFN- $\gamma$ and IL-6 in CD $11 b^{+}$cells increased significantly less in $\Delta y o p H$ infection compared to $\mathrm{pYV}^{+}$infection, suggesting that these cytokines might be necessary for control of $\mathrm{pYV}^{+}$but not of $\Delta y o p H$. From earlier studies, it is known that IFN- $\gamma$ and IL- 6 are crucial for clearance of Ye wild type infection $[22,23]$. To investigate whether these cytokines are in fact dispensable for the early defense against Ye lacking the virulence factor YopH, wild type (C57BL/6), IFN- $\gamma \mathrm{R}^{\%} \%$, and 
IL-6/- mice were infected with $\Delta y o p H$ or $\mathrm{pYV}^{+}$and the bacterial numbers in the spleen were determined. As shown in Figure 3, upon infection with $\mathrm{pYV}^{+}$the bacterial burden was higher at all investigated time points than in $\Delta y o p H$ infected IFN- $\gamma \mathrm{R} /-$, IL-6\% or wild type mice. 72 hours p.i., the bacterial burden was significantly higher $(\mathrm{p}<0.05)$ in spleens of IFN- $\gamma-\mathrm{R} \%$ and IL- $6 \%$ mice compared to wild type mice after infection with $\mathrm{pYV}^{+}$. In contrast, a similar bacterial burden was found in IFN- $\gamma \mathrm{R}^{-/}$and IL-6- mice compared to wild type mice after infection with $\Delta y o p H$. From this data, we conclude that IFN- $\gamma$ and IL- 6 are not necessarily required for the control of $\Delta y o p H$ infection at least in the early phase of infection.

\section{IFN- $\gamma$ pretreatment compensates YopH mediated} inhibition of bacterial killing by BMDM

To address whether the importance of IFN- $\gamma$, in counteracting Ye infection, could be linked to the defense against YopH mediated virulence, we investigated whether YopH may counteract the killing of yersiniae by BMDM. In addition, we tested whether IFN- $\gamma$ improves the killing of yersiniae by BMDMs. For this purpose, BMDM were cultured with and without IFN- $\gamma$ for $24 \mathrm{~h}$ and subsequently infected with either $\mathrm{pYV}^{+}$or $\Delta y o p H$. The number of bacteria was determined 0.25 hours after the infection of BMDM; alternatively BMDM were treated after 0.25 hours with gentamicin and the intracellular survival of bacteria was determined 3 and 5 hours after infection.

At 0.25 hours after the infection, the number of bacteria associated with BMDM was comparable in all groups (Figure 4) suggesting that neither pretreatment of BMDM with IFN- $\gamma$ nor YopH affects association of Ye with BMDM. At three hours p.i., $7 \%$ of $\mathrm{pYV}^{+}$and $2.1 \%$ of $\Delta y o p H$ were viable in BMDM cultured without IFN- $\gamma$ indicating that killing of $\Delta y o p H$ by BMDM cultured without IFN- $\gamma$ was significantly more effective than killing of $\mathrm{pYV}^{+}(\mathrm{p}<0.01)$. Interestingly, pretreatment of BMDM with IFN- $\gamma$ signifi-
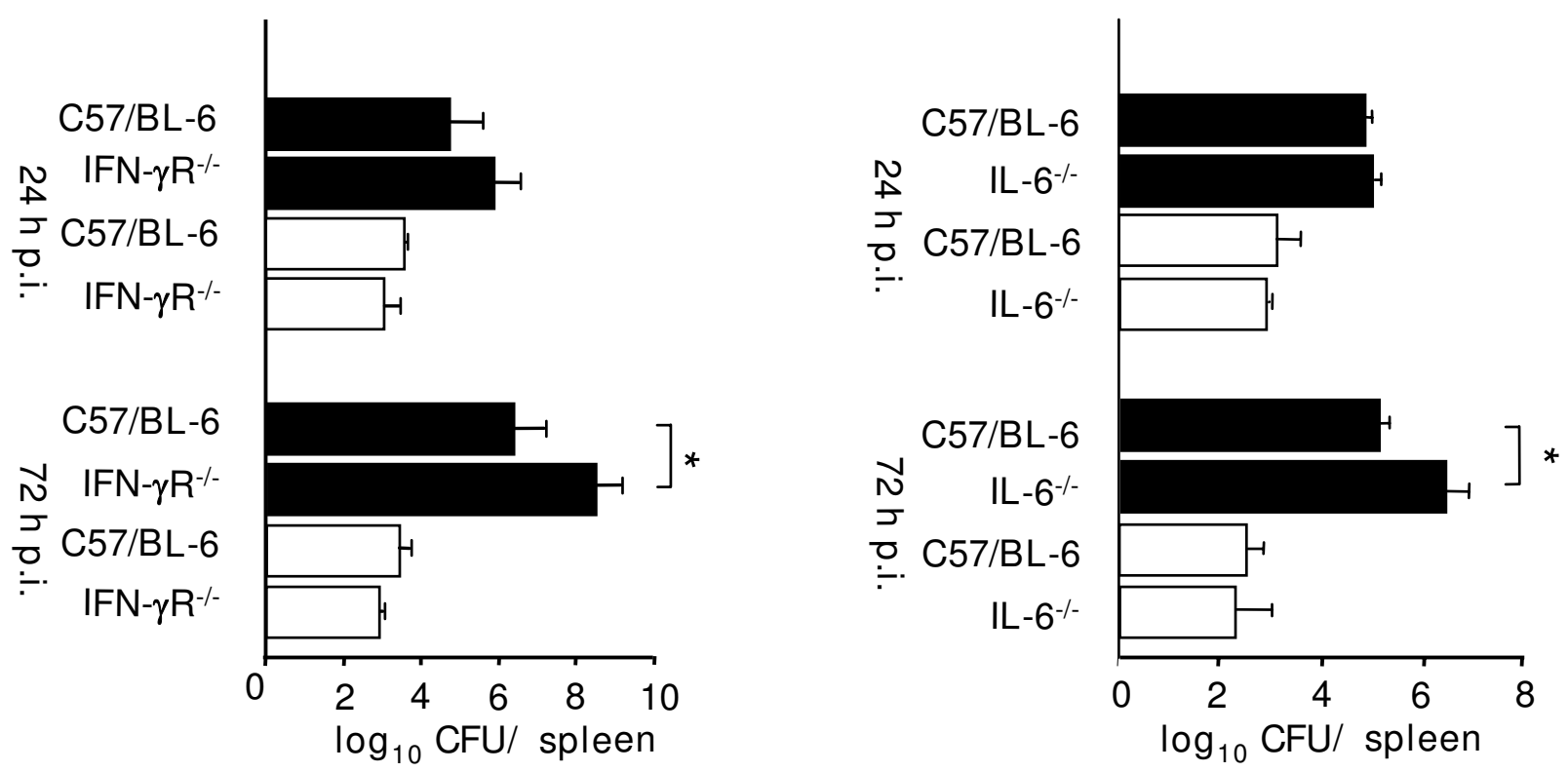

$\mathrm{pYV}^{+} \square \Delta y o p H$

\section{Figure 3}

IFN- $\gamma \mathbf{R}$ and IL-6 are not necessarily required for the control of Ye $\Delta$ yopH infection. IFN- $\gamma \mathrm{R}^{-/-}(\mathrm{A})$ or IL-6-/- (B) mice as well as C57BL/6 mice were infected intravenously with $5 \times 10^{4} \mathrm{pYV}^{+}$(black bars) or $5 \times 10^{4} \Delta y o p H$ (white bars). The bacterial number was assessed in spleens 24 and 72 hours after infection. Values represent the average log ${ }_{10}$ CFU per spleen with the standard errors of the means indicated by error bars (5-10 mice per group). Asterisks indicate significant differences ( $p<$ 0.05, Wilcoxon Rank test) between the compared groups. Two further independent experiments showed comparable results. 


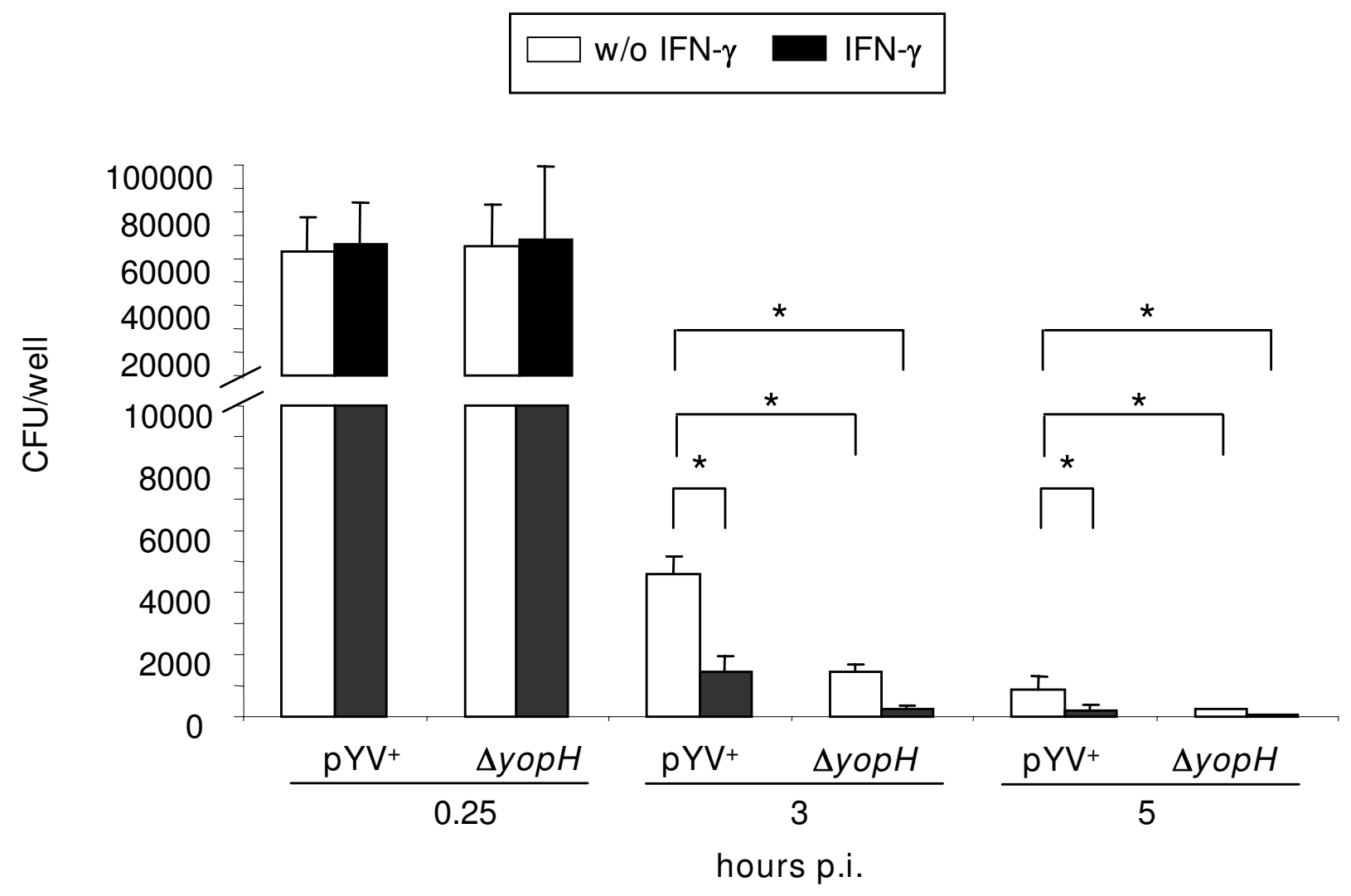

Figure 4

Survival of bacteria in BMDM. BMDM were either pretreated or not pretreated with IFN- $\gamma(50 \mathrm{ng} / \mathrm{ml})$ for $24 \mathrm{~h}$ and subsequently infected with $\mathrm{PYV}^{+}$or $\Delta y \mathrm{opH}$ with a MOI of 5 (C) for 0.25 or three hours as described in Material and Methods. Numbers of bacteria were determined by a CFU assay. The data represent the CFU \pm standard deviation of three independent experiments. All groups were compared for one point in time and asterisks indicate significant differences between the compared groups ( $p<0.05$, one-way ANOVA with Bonferroni correcctions).

cantly increased the killing of both $\mathrm{pYV}^{+}$and $\Delta y o p H$ by more than $60 \%$. This data indicates that the killing of $\mathrm{pYV}^{+}$by BMDM, pretreated with IFN- $\gamma$, is as effective as the killing of $\triangle y o p H$ by BMDM culture without IFN- $\gamma$, suggesting that IFN- $\gamma$ - mediated mechanisms are not necessarily required for $\Delta y o p H$ infection but contribute to an effective immune response to $\mathrm{pYV}^{+}$.

\section{Discussion and conclusion}

YopH is one of the most important virulence factors of Ye, which promotes colonization and survival of Ye in lymphoid tissues of mice. This capability appears to be attributed to its ability to inhibit phagocytosis $[5,24]$. and T cell activation through the intracytoplasmic action of YopH in phagocytes and T cells, respectively [15-17].

The goal of this study was to investigate whether and how YopH might interfere with the innate immune response in vivo. To this end, the gene expression profiles prior to and after infection with $\mathrm{pYV}^{+}$or $\Delta y o p H$ were analyzed in $\mathrm{CD} 11 \mathrm{~b}^{+}$cells from the spleen of infected mice. CD11b+ cells were chosen because they represent the most important spleen cell subpopulation involved in innate immune responses such as granulocytes, macrophages, and dendritic cells and have been demonstrated to be involved in or targeted by Ye infection.

The major problem with in vivo studies using Ye mutants is that mutations in major pathogenicity factors such as YopH affect virulence of Ye in vivo. Consequently, infection of mice with the same infection dose of wild type and mutant Ye ultimately results in different bacterial burden in infected organs. This gives rise to (i) different immune stimulation by Ye compounds and, as demonstrated herein, (ii) different recruitment of inflammatory cells and hence (iii) different composition of CD11 b+ spleen 
cell subpopulations. As a result, the differences in gene expression between wild type and mutant Ye might reflect both direct and indirect effects of virulence factors such as YopH. As an alternative, mice can be infected with different doses of wild type and mutant Ye, which will lead to comparable bacterial burden in infected organs such as the spleen. In this study we used both approaches and compared gene expression in mice infected with identical doses of wild type and mutant Ye (leading to different bacterial burden and clinical outcome) and variable doses (leading to comparable bacterial burden and clinical outcome). However, in the latter approach we could not rule out effects in gene expression that may result from different spleen cell subpopulations. Additional comparisons were performed, such as comparison of sublethal wildtype with lethal wildtype infection, as well as sublethal $\Delta y o p H$ with lethal $\Delta y o p H$ infection because the information obtained was mostly redundant to those already received with the comparisons discussed below.

We focused on the differences in genes known to be involved in immune responses. Sublethal $\mathrm{pYV}^{+}$and lethal $\Delta y o p H$ infection results in the same bacterial burden in the spleen but shows some differences in the composition of the cell populations expressing $\mathrm{CD} 11 \mathrm{~b}$ such as granulocytes, macrophages and dendritic cells. However, comparison of the expression between sublethal $\mathrm{pYV}^{+}$and lethal $\Delta y o p H$ infection reveals that acute phase reactants and other genes involved in innate immune response such as the antimicrobial component lactoferrin and MARCO (playing a role in clearance of pneumococcal infections) [25] are increased after $\Delta y o p H$ infection compared to $\mathrm{pYV}^{+}$infection. Since acute phase reactants are predominantly constitutively expressed, the differences in gene expression after sublethal $\mathrm{pYV}^{+}$and lethal $\Delta y o p H$ infection may be due to changes in the composition of the cell populations which express CD11b but nevertheless may be also associated with lethal course of $\Delta y o p H$ infection.

IL-10 and CCL17 were found to be higher expressed after sublethal $\mathrm{pYV}^{+}$versus lethal $\mathrm{pYV}^{+}$infection as well as after sublethal versus lethal $\Delta y o p H$ infection, respectively. Since each of these conditions was associated with a comparable composition of the cell populations expressing $\mathrm{CD} 11 \mathrm{~b}$ in the spleen we conclude that increased expression of IL-10 and CCL17 is not due to differences in the composition of $\mathrm{CD} 11 \mathrm{~b}^{+}$cells. Previous studies suggested that the secreted Ye protein LcrV of $\mathrm{O} 8$ strains binds to TLR2 and triggers increased IL-10 secretion in macrophages [26]. In line with this, it was shown that infection with an inocolum of $\mathrm{pYV}^{+}$which is lethal for wildtype mice can be survived by IL-10\%- mice [27] indicating that IL-10 is a marker for lethal or sublethal course of infection. However, this might not be a general observation for all Yersinia strains or species since TLR2 activity and prob- ably IL-10 secretion induced by LcrV vary due to a hypervariable region in the N-terminus of LcrV [28]. In addition, the highest TLR2 activity was found for O8 strains as used in this study. Likewise, CCL17, a chemokine which attracts Th2 and regulatory T cells [29-31]. could also be involved in driving infections in direction of a lethal course; this, however, has to be more thorougly investigated in further studies.

Since a high number of genes showed a lower expression after sublethal $\Delta y o p H$ infection we focused predominantly on this aspect. Within this group several proinflammatory response genes dependent on TLR signaling such as IL-12, CXCL1, CXCL2 and TNF- $\alpha$ but also IFN- $\gamma$ were predominantly found. Since cytokines and chemokines act as secreted proteins the overall expression levels may be of more relevance than the subpopulation of cells which expresses these genes. In addition, histidine decarboxylase was found in this group of genes. The expression of histidine decarboxylase seems to reflect the importance of histamine signaling for control of Ye infection [32]. The improved reduction of the bacterial burden as found after infection with a sublethal dose of $\Delta y o p H$ is associated with a lower expression of such genes. The weaker immune response found after infection with $\Delta y o p H$ may reflect the more effective clearance of bacteria but may also raise the possibility that components of this immune response are no longer required to control the infection. Previous data suggested that IL-12, IL-18 and TNF- $\alpha$ may not be required for clearance of $\Delta y o p H$ infection [19]. In line with these findings we have shown that IFN- $\gamma$ and IL-6 may also not be required for clearance of a $\Delta y o p H$ infection. Thus, clearance of infection in the spleen is comparable in C57BL/6 and congenic IFN- $\gamma \mathrm{R}^{-/}$mice. Similar experiments were performed using IL- $6 \%$ mice, indicating that IL-6 is not necessarily required for clearance of $\Delta y o p H$ infection.

Other groups found that oral infection of BALB/c mice with a $Y$. pseudotuberculosis yopH mutant resulted in a similar bacterial burden in the spleen five days after infection of IFN- $\gamma^{-/-}$and IFN- $\gamma^{+/+}$mice $[20,21]$. Interestingly, by coinfection of $Y$. pseudotuberculosis wild type and $ү о р H$ mutant it has been demonstrated that in the presence of IFN- $\gamma$ the $\gamma o p H$ mutant is more efficiently killed in comparison to wild type. On the contrary, in the absence of IFN- $\gamma$ the survival advantage of the wildtype $Y$. pseudotuberculosis compared to the yopH mutant is much weaker [20]. This data supports the view that IFN- $\gamma$ is required for clearance of wildtype Yersinia [22] but plays a minor role for clearance of $\Delta y o p H$ mutant and would explain at least in this case similarities between $Y$. pseudotuberculosis and Ye infection of mice. 
There is substantial knowledge about IFN- $\gamma$ mediated effector mechanisms in host defense against pathogens, such as promotion of TH1 responses, induction of expression of $47 \mathrm{kDa}$ GTPases [33], oxidative burst or antigen presentation [34]; however, the exact effector mechanisms induced by IFN- $\gamma$ for clearance of a Yersinia infection are not yet defined. By determining killing of BMDM upon infection with Ye we demonstrate that killing of yersiniae by BMDM is quite efficient. However, in contrast to $\Delta y o p H, \mathrm{pYV}^{+}$is less efficiently cleared by BMDM indicating that YopH inhibits killing of yersiniae to some extent. In addition pretreatment of BMDM with IFN- $\gamma$ bypasses indirectly or directly YopH mediated resistance of killing of yersiniae. This data further supports the idea that IFN- $\gamma$ is not necessarily needed to defeat Yersinia lacking YopH. However, YopH may also exert other immune evasion mechanisms. In fact, YopH also inhibits $\mathrm{T}$ cell activation [15-17]. Previous data demonstrates that infection of athymic, T cell deficient C57BL/ 6 nude mice leads to an increased bacterial number in the spleen starting only three days after infection compared to infection with C57BL/ 6 mice suggesting that $\mathrm{T}$ cell responses are already involved in the early phase of Ye infections [35].

Taken together, the data presented herein show that IFN$\gamma$ bypasses or compensates for immune evasion mechanism of YopH. Moreover, we provide evidence that improvement in killing of bacteria by macrophages may represent part of the effector functions of IFN- $\gamma$ to compensate for immune evasion mechanisms provided by the interplay of the effector Yops of the Ysc-Yop type three secretion system and that deletion of YopH enables the immune defense to work efficiently without the presence of IFN- $\gamma$. However, further studies need to define whether alterations in the immune response against YopH deletion mutant are solely due to the phosphatase activity of YopH or whether they also may be due to changes in the secretion of some of the other Yops (e.g. YopT, YopP) [36]. Moreover, future studies are needed to define the crucial mechanisms important for clearance of Yersinia infection in vivo and to elucidate which IFN- $\gamma$ induced genes are important to bypass Yersinia mediated inhibition of yersiniae killing. However, since beside IFN- $\gamma$ other genes such as IL-6, TNF- $\alpha$, IL-12, IL-18 are not necessarily required for clearance of Ye infection with $\Delta y o p H$, it can be speculated that YopH does not counteract the effector functions of one of those genes specifically but rather a proinflammatory response in general.

\section{Methods}

\section{Bacterial strains and plasmids}

For infection the Ye O:8 strain WA-314 (pYV+) [37], and derivatives of this strain were used. The strain WA-C (pYV) lacks the pYV virulence plasmid and the strain WA-C pYV yopH $\Delta 17-455$ ( $\Delta$ yopH) lacks YopH [36].

\section{Mouse infections}

The mouse strains used were C57BL/6j-IL-6 ${ }^{\text {tm1 } 1 \text { Kopf }}$ (referred as IL-6-/-) kindly provided by M. Kopf, ETH Zürich, Switzerland [38] C57BL/6J-Ifngrtm 1agt IFN- $\gamma \mathrm{R}^{-/-}$[39] purchased by Jackson laboratories and corresponding C57BL/ 6 wildtype mice. Six- to eight-week-old female C57BL/6 mice were infected intravenously with the indicated doses of Ye strains from frozen stock suspensions. The administered dose was determined by plating serial dilutions on Mueller-Hinton agar for $36 \mathrm{~h}$ at $27^{\circ} \mathrm{C}$. For kinetic analysis, mice were asphyxiated using $\mathrm{CO}_{2}$ at various time points post infection. Spleens were aseptically removed and homogenized in $5 \mathrm{ml}$ HBSS-buffer (Hank's Balance solution supplemented with $2 \%$ FCS and $10 \mathrm{mM}$ HEPES). To determine the numbers of CFU/organ, serial dilutions of homogenated organs were plated on Mueller-Hinton agar plates. Infection experiments were approved according to German law by the Regierungspräsidium Tübingen (H2/ 02).

\section{Selection of splenic CDI I $b^{+}$cells}

For the selection of splenic CD $11 b^{+}$cells for further use in microarray experiments five to ten mice per group were sacrificed by $\mathrm{CO}_{2}$ asphyxiation. The spleens were removed and placed in ice-cold HBSS $\left(\mathrm{Ca}^{2+}\right.$ and $\mathrm{Mg}^{2+}$ free Hanks' balanced salt solution; BioWhittaker, Walkersville, MD), supplemented with 2\% FCS (HyClone, Logan, Utah) and $10 \mathrm{mM}$ HEPES buffer. The spleens were forced with a $5 \mathrm{ml}$ syringe pestle through a $100 \mu \mathrm{m}$-pore nylon mesh cell strainer (Falcon; BD Biosciences). Red blood cells were lysed from spleen samples by incubating the cell suspensions for $5 \mathrm{~min}$ at room temperature in erythrocyte lysis buffer (170 mM Tris, $160 \mathrm{mM} \mathrm{NH}_{4} \mathrm{Cl}$, pH 7.4) followed by two washes in ice-cold HBSS. CD $11 b^{+}$cells from a pool of five to ten mice per group were purified by positive selection using magnetic activated cell sorting (MACS) ${ }^{\circledast}$ CD11b MicroBeads (Miltenyi Biotec) according to the manufacturer's instructions. To ensure enrichment values of 96-98\% purity, the magnetic separation was performed twice. Cell viability and number were assessed by trypan blue exclusion.

\section{Flow cytometry}

Splenic single-cell suspensions were obtained as described above. $1 \times 10^{6}$ cells were resuspended in $100 \mu \mathrm{l}$ FACS buffer and stained with surface marker-specific fluorophore-conjugated antibodies (Abs). The following Abs and secondary staining reagents conjugated with different fluorophores were used for flow cytometric studies: rat anti-mouse Ly-6G (Gr-1: RB6-8C5), rat anti-mouse CD4 (RM4-5), rat anti-mouse CD8a (53-6.7) or rat anti-mouse CD45R/B220 (RA3-6B2); rat anti-mouse CD19 (1D3), rat anti-mouse pan-NK-cell (DX5), rat anti-mouse CD3 $\varepsilon$ chain (145-2C11) and the hamster anti-mouse CD11C (HL3), rat anti-mouse CD11b (M1/70), streptavidin- 
FITC, streptavidin-PE; all from BD Pharmingen, Heidelberg, Germany. The rat anti-mouse F4/80 (CI:A3-1) and rat anti-mouse MARCO (ED31) from Serotec (Serotec, Oxford, UK) were also used. The specificity of the staining was verified by the use of isotype control mAbs. Samples were analyzed on a FACSCalibur flow cytometer (BD Immunocytometry Systems) with gating on the propidium iodide-negative cells.

\section{Isolation of total RNA and microarray analysis}

Total RNA was extracted from CD $11 \mathrm{~b}^{+}$cells derived from a pool of five to ten mice per group using the RNAeasy mini-kit following the manufacturer's instructions (Qiagen, Hilden, Germany). Generation of fragmented cRNA was performed as recently described [40] and used for hybridization onto MG-U74Av2 from Affymetrix (Affymetrix, High Wycombe, UK). Genechips were washed, stained with streptavidin-phycoerythrin and read using a GeneChip Scanner 2500 (Affymetrix) at the IZKF microarray facility, Tübingen.

\section{Microarray data analysis}

Analysis of microarray data was performed using the Affymetrix Microarray Suite 5.0, Affymetrix MicroDB 3.0 and Affymetrix Data Mining Tool 3.0. All array experiments were scaled to a target intensity of 150 , otherwise the default values of the Microarray suite were used. Filtering of the results was performed as follows: signal $\log _{2}$ ratios (SLR) of the experiments for each colonization condition and time point was calculated. A median SLR greater than 1.5 or less than -1.5 was considered as significant change. The absolute detection calls and change calls were assigned using the detection p-values or the change $\mathrm{p}$-values. A detection $\mathrm{p}$-value of $\leq 0.04$ was considered as present $(\mathrm{P})$, a detection $\mathrm{p}$-value of $>0.04$ and $\leq 0.06$ was considered marginal $(\mathrm{M})$ and a detection p-value $>0.06$ was considered absent (A). A change call of increase (I) was assigned with a median change p-value of $\leq 0.0025$ and a change call of marginal increase (MI) was assigned at a median change p-value $>0.0025$ to 0.003 . Change calls of marginal decrease (MD) were assigned at a median change p-value of $\geq 0.997$ to $<0.998$ and a change call of decrease (D) was assigned at a p-value $\geq 0.998$. All others were assigned no change (NC). Of the probe sets with a significant SLR that had a change call other than NC in comparison to uninfected and were not absent in both compared groups were retained. Probe sets with an increase but a detection call of A in the infected cells were also discarded. Of the remaining probe sets only those with a signal at least 3 times higher than the average noise were used for further analysis. The magnitude and direction of expression changes were estimated as Signal Log Ratio (SLR). Microarray data have been deposited in NCBIs Gene Expression Omnibus (GEO, http:// www.ncbi.nlm.nih.gov/geo/ accession number (GSE
11189). For each condition described here one microarray was used.

\section{Cluster analysis}

For Cluster analysis we used Genesis, release 1.6.0 (Institute for Genomics and Bioinformatics, University of Technology, Graz, http://genome.tugraz.at). To analyze the relationship between groups of genes we performed a kmeans clustering with a number of 10 clusters and a maximum of 200 iterations. Categorization was based on the NetAffx database http://www.NetAffx.com.

\section{Quantitative RT- PCR analysis}

Total RNA from CD11 b+ cells was extracted using the RNeasy Mini Kit (Qiagen). $2 \mu \mathrm{g}$ of RNA were reverse transcribed as described [41]. Real-time RT-PCR was carried out on a GeneAmp 5700 Sequence Detection System (Applied Biosystems, Darmstadt, Germany). Each 20- $\mu \mathrm{l}$ reaction contained $10 \mu \mathrm{l}$ Platinum Quantitative PCR SuperMix-UDG (Invitrogen, Karlsruhe, Germany), $0.4 \mu \mathrm{l}$ ROX Reference Dye (Invitrogen, Karlsruhe, Germany), 3.6 $\mu \mathrm{l}$ PCR grade water, $1 \mu \mathrm{l}$ target gene specific Assay-onDemand Gene Expression Assay Mix Mm00446190_m1 for mouse IL-6, Mm00443258_m1 for mouse TNF- $\alpha$, Mm00434165_m1 for mouse IL-12 p35, Mm00440265_m1 for mouse MARCO, or Mm00657299_g1 for mouse RPL8 (including primers and dye-labeled hybridization probes; Applied Biosystems, Darmstadt, Germany), and $5 \mu \mathrm{l}$ cDNA. Thermal cycling conditions for all reactions were as follows: $2 \mathrm{~min}$ at $50^{\circ} \mathrm{C}, 10 \mathrm{~min}$ at $95^{\circ} \mathrm{C}$, then 40 cycles of $15 \mathrm{~s}$ at $95^{\circ} \mathrm{C}$ and $1 \mathrm{~min}$ at $60^{\circ} \mathrm{C}$. Results were quantified using the $2^{-}$ $\Delta \Delta \mathrm{C}_{\mathrm{T}}$ method $[42,43]$. Cytokine mRNA expression levels were normalized to the expression of the houskeeping gene ribosomal protein L8 (RPL8). All PCR experiments were performed in duplicate, and standard deviations were calculated and displayed as error bars.

\section{Analysis of intracellular survival by CFU assay}

Intracellular survival was determined with modification as previously described [44]. $2 \times 10^{5} \mathrm{BMDM}$ resuspended in DMEM (Invitrogen, Karlsruhe, Germany), containing $10 \%$ FCS (Sigma, Taufkirchen, Germany), supplemented with Na-pyruvate at $1 \mathrm{mM}$ (Biochrom, Berlin, Germany), and $2 \mathrm{mM}$ L-glutamine (Invitrogen, Karlsruhe, Germany) were seeded into 24 well cell culture plates and incubated overnight. Bacteria were grown overnight at $27^{\circ} \mathrm{C}$ in $\mathrm{LB}$ medium and subcultivated for $2 \mathrm{~h}$ at $37^{\circ} \mathrm{C}$. The bacteria were washed twice with PBS and finally diluted as needed in DMEM supplemented with $10 \%$ heat inactivated fetal calf serum, $2 \mathrm{mM}$ L-glutamine and $1 \mathrm{mM}$ Na-pyruvate. The bacterial number was diluted to a MOI of 5 . After addition of bacteria cell culture plates were centrifuged for 5 minutes at $200 \times \mathrm{g}$ to facilitate contact of bacteria. After 15 minutes of infection cells were washed twice with PBS. 
Some of the wells were used to determine initial number of cell associated bacteria by a CFU assay. To the remaining cells cell culture medium containing $8 \mu \mathrm{g}$ per ml gentamicin was added. After one hour the medium was removed and complete cell culture medium was added containing $4.5 \mathrm{mg} / \mathrm{ml}$ gentamicin. Three or five hours after infection a CFU assay was performed as described recently [44].

\section{Statistics}

The data shown in the figures are from representative experiments. Differences between mean values were analyzed as indicated using either Wilcoxon Rank test, one way ANOVA analyses or logrank test by using Graph Pad Prism software http://www.graphpad.com/. A $p$ value of $<$ 0.05 was considered statistically significant.

\section{Authors' contributions}

GM, EF and PW were equal partners in the production of these findings and all three participated in the design of the study and carried out the infection experiments, ex vivo and in vitro experiments, performed data analyses and helped to draft the manuscript. SM guided and supported performance of the microarray analyses. MB processed the RNA for microarray experiments and performed microarray experiments. IBA participated in the study design, data analysis and draft of the manuscript. EB conceived of the study, carried out the design and coordination and drafted the manuscript.

\section{Additional material}

\section{Additional file 1}

Comparison of sublethal $p \mathrm{YV}^{+}$versus sublethal $\triangle \mathrm{yopH}$ infection. List of genes which fulfill the criteria that signal $\log _{2}$ ratio (SLR) after sublethal $p \mathrm{YV}^{+}$(infection with $5 \times 10^{3} \mathrm{Ye}$ ) compared to sublethal $\Delta \mathrm{yopH}$ infection (infection with $5 \times 10^{4} \mathrm{Ye}$ ) is $>1.5$ or $<-1.5$. Expression levels of genes after infection with sublethal or lethal $\mathrm{pYV}^{+}$as well as $\Delta \mathrm{yopH}$ infection are depicted as fold induction compared to uninfected mice. Click here for file

[http://www.biomedcentral.com/content/supplementary/14712180-8-153-S1.xls]

\section{Additional file 2}

Comparison of sublethal $p \mathrm{YV}^{+}$versus lethal $\triangle \mathrm{yopH}$ infection. List of genes which fulfill the criteria that signal $\log _{2}$ ratio (SLR) after sublethal $p \mathrm{YV}^{+}$(infection with $5 \times 10^{3} \mathrm{Ye}$ ) compared to sublethal $\triangle \mathrm{yopH}$ infection (infection with $5 \times 10^{6} \mathrm{Ye}$ ) is $>1.5$ or $<-1.5$. Expression levels of genes after infection with sublethal or lethal $\mathrm{pYV}^{+}$as well as $\Delta \mathrm{yopH}$ infection are depicted as fold induction compared to uninfected mice.

Click here for file

[http://www.biomedcentral.com/content/supplementary/14712180-8-153-S2.xls]

\section{Acknowledgements}

We would like to thank Juliane Klenk for outstanding technical assistance and Fiona O'Rourke and Amro Amr for proofreading. This work was supported by the BMBF, National genome research network. GM was supported by a Marie-Curie grant of the EU.

\section{References}

I. Smego RA, Frean J, Koornhof HJ: Yersiniosis I: microbiological and clinicoepidemiological aspects of plague and non-plague Yersinia infections. Eur J Clin Microbiol Infect Dis 1999, 18: I-15.

2. Koornhof HJ, Smego RA Jr, Nicol M: Yersiniosis. II: The pathogenesis of Yersinia infections. Eur J Clin Microbiol Infect Dis 1999, 18:87-II2.

3. Cornelis GR: The Yersinia Ysc-Yop 'type III' weaponry. Nat Rev Mol Cell Biol 2002, 3:742-752.

4. Fallman M, Andersson K, Hakansson S, Magnusson KE, Stendahl O, Wolf-Watz H: Yersinia pseudotuberculosis inhibits Fc receptormediated phagocytosis in $\mathbf{J 7 7 4}$ cells. Infect Immun 1995, 63:3117-3124.

5. Grosdent N, Maridonneau-Parini I, Sory MP, Cornelis GR: Role of Yops and adhesins in resistance of Yersinia enterocolitica to phagocytosis. Infect Immun 2002, 70:4I65-4I76.

6. Rosqvist R, Forsberg A, Rimpilainen M, Bergman T, Wolf Watz H: The cytotoxic protein YopE of Yersinia obstructs the primary host defence. Mol Microbiol 1990, 4:657-667.

7. Bliska JB, Black DS: Inhibition of the Fc receptor-mediated oxidative burst in macrophages by the Yersinia pseudotuberculosis tyrosine phosphatase. Infect Immun 1995, 63:68I-685.

8. Persson $C$, Nordfelth R, Andersson K, Forsberg A, Wolf-Watz $H$, Fallman M: Localization of the Yersinia PTPase to focal complexes is an important virulence mechanism. Mol Microbiol 1999, 33:828-838.

9. Black DS, Bliska JB: Identification of $\mathrm{p} / 30$ Cas as a substrate of Yersinia YopH (Yop5I), a bacterial protein tyrosine phosphatase that translocates into mammalian cells and targets focal adhesions. $E M B O \mathrm{~J} 1997,16: 2730-2744$.

10. Hamid N, Gustavsson A, Andersson K, McGee K, Persson C, Rudd CE, Fällman M: YopH dephosphorylates Cas and Fyn-binding protein in macrophages. Microb Pathog 1999, 27:23I-242.

II. Black DS, Montagna LG, Zitsmann S, Bliska JB: Identification of an amino-terminal substrate-binding domain in the Yersinia tyrosine phosphatase that is required for efficient recognition of focal adhesion targets. Mol Microbiol I998, 29: I 263-I 274.

12. Persson C, Carballeira N, Wolf-Watz H, Fallman M: The PTPase YopH inhibits uptake of Yersinia, tyrosine phosphorylation of pI30Cas and FAK, and the associated accumulation of these proteins in peripheral focal adhesions. EMBO J 1997, 16:2307-2318.

13. Deleuil F, Mogemark L, Francis MS, Wolf-Watz H, Fallman M: Interaction between the Yersinia protein tyrosine phosphatase YopH and eukaryotic Cas/Fyb is an important virulence mechanism. Cell Microbiol 2003, 5:53-64.

14. Sauvonnet N, Lambermont I, van der BP, Cornelis GR: YopH prevents monocyte chemoattractant protein I expression in macrophages and T-cell proliferation through inactivation of the phosphatidylinositol 3-kinase pathway. Mol Microbiol 2002, 45:805-8I5.

15. Yao T, Mecsas J, Healy Jl, Falkow S, Chien Y: Suppression of T and B lymphocyte activation by a Yersinia pseudotuberculosis virulence factor, yopH. J Exp Med 1999, 190:1343-1350.

16. Alonso A, Bottini N, Bruckner S, Rahmouni S, Williams S, Schoenberger SP, Mustelin T: Lck dephosphorylation at Tyr-394 and inhibition of $\mathbf{T}$ cell antigen receptor signaling by Yersinia phosphatase YopH. J Biol Chem 2004, 279:4922-4928.

17. Gerke C, Falkow S, Chien YH: The adaptor molecules LAT and SLP-76 are specifically targeted by Yersinia to inhibit $T$ cell activation. J Exp Med 2005, 20I:36I-37I.

18. Trulzsch K, Sporleder T, Igwe EI, Russmann H, Heesemann J: Contribution of the major secreted yops of Yersinia enterocolitica O:8 to pathogenicity in the mouse infection model. Infect Immun 2004, 72:5227-5234.

19. Di Genaro MS, Waidmann M, Kramer U, Hitziger N, Bohn E, Autenrieth IB: Attenuated Yersinia enterocolitica mutant strains exhibit differential virulence in cytokine-deficient mice: 
implications for the development of novel live carrier vaccines. Infect Immun 2003, 7 I: 1804-18I2.

20. Logsdon LK, Mecsas J: The proinflammatory response induced by wild-type Yersinia pseudotuberculosis infection inhibits survival of yop mutants in the gastrointestinal tract and Peyer's patches. Infect Immun 2006, 74: I5I6-I527.

21. Logsdon LK, Mecsas J: Requirement of the Yersinia pseudotuberculosis effectors YopH and YopE in colonization and persistence in intestinal and lymph tissues. Infect Immun 2003, $71: 4595-4607$.

22. Bohn E, Schmitt E, Bielfeldt C, Noll A, Schulte R, Autenrieth IB: Ambiguous role of interleukin- 12 in Yersinia enterocolitica infection in susceptible and resistant mouse strains. Infect Immun 1998, 66:2213-2220.

23. Dube PH, Handley SA, Lewis J, Miller VL: Protective role of interleukin-6 during Yersinia enterocolitica infection is mediated through the modulation of inflammatory cytokines. Infect Immun 2004, 72:356I-3570.

24. Fallman M, Deleuil F, McGee K: Resistance to phagocytosis by Yersinia. Int J Med Microbiol 2002, 29 I:50I-509.

25. Arredouani M, Yang Z, Ning Y, Qin G, Soininen R, Tryggvason K, Kobzik $L$ : The scavenger receptor MARCO is required for lung defense against pneumococcal pneumonia and inhaled particles. J Exp Med 2004, 200:267-272.

26. Sing A, Rost D, Tvardovskaia N, Roggenkamp A, Wiedemann A, Kirschning Cl, Aepfelbacher M, Heesemann J: Yersinia V-antigen exploits toll-like receptor 2 and CDI 4 for interleukin 10 mediated immunosuppression. J Exp Med 2002, 196:1017-1024

27. Sing A, Roggenkamp A, Geiger AM, Heesemann J: Yersinia enterocolitica evasion of the host innate immune response by $V$ antigen-induced IL- 10 production of macrophages is abrogated in IL-I 0-deficient mice. J Immunol 2002, I68:|3| 5-|32|.

28. Sing A, Reithmeier-Rost D, Granfors K, Hill J, Roggenkamp A, Heesemann J: A hypervariable $\mathbf{N}$-terminal region of Yersinia LcrV determines Toll-like receptor 2-mediated IL- 10 induction and mouse virulence. Proc Natl Acad Sci USA 2005 102: I6049-16054

29. lellem A, Mariani M, Lang R, Recalde H, Panina-Bordignon P, Sinigaglia $F, D$ 'Ambrosio $D$ : Unique chemotactic response profile and specific expression of chemokine receptors CCR4 and CCR8 by CD4(+)CD25(+) regulatory $\mathbf{T}$ cells. J Exp Med 200I, 194:847-853.

30. Imai T, Nagira M, Takagi S, Kakizaki M, Nishimura M, Wang J, Gray PW, Maatsushima K, Yoshie O: Selective recruitment of CCR4bearing Th2 cells toward antigen-presenting cells by the $C C$ chemokines thymus and activation-regulated chemokine and macrophage-derived chemokine. Int Immunol 1999, I I:8I-88.

31. Yoshie O, Imai T, Nomiyama $\mathrm{H}$ : Chemokines in immunity. Adv Immunol 200I, 78:57-IIO.

32. Handley SA, Dube PH, Miller VL: Histamine signaling through the $H(2)$ receptor in the Peyer's patch is important for controlling Yersinia enterocolitica infection. Proc Natl Acad Sci USA 2006, 103:9268-9273.

33. Taylor GA, Feng CG, Sher A: p47 GTPases: regulators of immunity to intracellular pathogens. Nat Rev Immunol 2004, 4:100-109.

34. Ellis TN, Beaman BL: Interferon-gamma activation of polymorphonuclear neutrophil function. Immunology 2004, I | 2:2- 12.

35. Autenrieth IB, Vogel U, Preger S, Heymer B, Heesemann J: Experimental Yersinia enterocolitica infection in euthymic and $T$ cell-deficient athymic nude C57BL/6 mice: comparison of time course, histomorphology, and immune response. Infect Immun 1993, 61:2585-2595.

36. Adkins I, Koberle M, Grobner S, Bohn E, Autenrieth IB, Borgmann S: Yersinia outer proteins $E, H, P$, and T differentially target the cytoskeleton and inhibit phagocytic capacity of dendritic cells. Int J Med Microbiol 2007.

37. Heesemann J, Laufs R: Construction of a mobilizable Yersinia enterocolitica virulence plasmid. I Bacteriol 1983, I55:76I-767.

38. Kopf M, Baumann H, Freer G, Freudenberg M, Lamers M, Kishimoto T, Zinkernagel R, Bluethmann H, Köhler G: Impaired immune and acute-phase responses in interleukin-6-deficient mice. Nature 1994, 368:339-342.

39. Huang S, Hendriks W, Althage A, Hemmi S, Bluethmann H, Kamijo R, Vilcek J, Ziinkernagel RM, Aguet M: Immune response in mice that lack the interferon-gamma receptor. Science 1993 , 259: 1742-1745.

40. Bohn E, Müller S, Lauber J, Geffers R, Speer N, Spieth C, Krjci J, Manncke B, Buer J, Zell A, Autenrieth IB: Gene expression patterns of epithelial cells modulated by pathogenicity factors of Yersinia enterocolitica. Cell Microbiol 2004, 6:|29-|4I.

4I. Schulte R, Autenrieth IB: Yersinia enterocolitica-induced interleukin-8 secretion by human intestinal epithelial cells depends on cell differentiation. Infect Immun 1998, 66: $1216-1224$.

42. Pfaffl MW: A new mathematical model for relative quantification in real-time RT-PCR. Nucleic Acids Res 2001, 29:e45.

43. Schmittgen TD: Real-time quantitative PCR. Methods 200I, 25:383-385

44. Grabenstein JP, Marceau M, Pujol C, Simonet M, Bliska JB: The response regulator PhoP of Yersinia pseudotuberculosis is important for replication in macrophages and for virulence. Infect Immun 2004, 72:4973-4984.
Publish with Biomed Central and every scientist can read your work free of charge

"BioMed Central will be the most significant development for disseminating the results of biomedical research in our lifetime. "

Sir Paul Nurse, Cancer Research UK

Your research papers will be:

- available free of charge to the entire biomedical community

- peer reviewed and published immediately upon acceptance

- cited in PubMed and archived on PubMed Central

- yours - you keep the copyright
BioMedcentral 